\title{
Development of strategies for changing in physical activity behaviors on older adults with disabilities
}

\author{
Kyo-Man Koo' ${ }^{1}$, Chae-Hee Park, ${ }^{2 *}$, Chun-Jong Kim ${ }^{3}$ \\ 'Department of Adapted Physical Education, Baekseok University, Cheonan, Korea \\ ${ }^{2}$ Department of Sport and Healthy Aging, Korea National Sport University, Seoul, Korea \\ ${ }^{3}$ Department of Special Physical Education, Yeungnam University, Gyeongsan, Korea
}

The purpose of this study was to develop strategies for promoting physical activity for the disabled older adults who were in the transtheoretical model of precontemplation, contemplation, and preparation stages about participating physical activities for promoting healthy life-styles. In order to achieve this goal, we developed a preliminary strategy for promoting physical activity for the elderly with disabilities based on the data gathered through the ground-work studies and the results of the research on the changes of the exercise behavior directly investigated from the elderly with disabilities. Then the strategies were verified to completion of the final promoting strategies. The elderly with disabilities in the three stages of precontemplation, contemplation, and preparation should develop strategies to think positively about themselves and their surroundings as well as strengthen their appropriate healthy behaviors. Additionally, families, physicians, and healthy seniors who spent time with disabled older adults could help to promote physical activities. However, overall administrative support, in-stitutional system construction, and public policy support were needed and it suggested that multifaceted supports and a variety of cooperation were necessary to improve a quality of life among older adults with disabilities.

Keywords: Older adults with disability, Physical activity behaviors, Stages of change

\section{INTRODUCTION}

The elderly with disabilities are individuals who meet two conditions: disability and the elderly (Foreman, 1998). They are categorized as "age with disability" and "disability with aging" according to the time of the disability (Sheets, 2005; Verbrugge and Yang, 2002). The elderly with disabilities refers to the elderly who experience difficulties inherently or timely, and who are unable to live independently due to diseases or accidents due to aging (Yang and Shin, 2011).

In general, these groups have been reported to have a low quality of life due to physical weakness and deterioration and psychological stress about bad health as well as a variety of health problems (Campbell and Kemp, 1997; Sheets, 2005; Verbrugge and Yang, 2002). Activities of daily living and instrumental activities of daily living, which are closely related to the quality of life of the individual, are underestimated (Yang and Shin, 2011). Therefore, regular physical activity participation is emphasized not only for the elderly but also for the elderly with disabilities. Regular physical activity is an effective method of primary prevention that reduces the chronic diseases such as diabetes, cardiovascular disease, cancer, and osteoporosis, and secondary prevention to delay disease progression (Warburton et al., 2006).

Previous studies have shown that physical activity improves physical functioning in elderly people with arthritis (Mangani et al., 2006) and an positive effect on pain reduction (Tak et al., 2005). In addition, if a person has severe obesity, a level of physical disability can be high, but physical activity can lower the body fat rate and alleviate it (Di Francesco et al., 2005; Rejeski et al., 2010). Furthermore, in the case of the frail elderly, physical activity has positive effects on reducing fear of falls and self-assessment of health conditions (Giné-Garriga et al., 2013; Riebe et al., 2009). As a re-
${ }^{*}$ Corresponding author: Chae-Hee Park (bi) https://orcid.org/0000-0001-8880-3729 Department of Sport and Healthy Aging, Korea National Sport University, 1239 Yangjae-daero, Songpa-gu, Seoul 05541, Korea

Tel: +82-2-410-6953, Fax: +82-2-418-1877, E-mail: chaepark@knsu.ac.kr Received: October 18, 2017 / Accepted: December 9, 2017
This is an Open Access article distributed under the terms of the Creative Commons Attribution Non-Commercial License (http://creativecommons.org/licenses/by-nc/4.0/) which permits unrestricted non-commercial use, distribution, and reproduction in any medium, provided the original work is properly cited. 
sult of many studies, physical activity can be expected to play an important role in the health of the elderly with disabilities.

However, in the survey of general elderly in Korea, participation rate of physical activity such as mountain climbing and walking was $10.5 \%$ and $7.0 \%$ (Ministry of Health and Welfare, 2012), and the survey showed that the rate of regular sports activities of disabled people was only $15.8 \%$ (Korean Paralympic Committee, 2011). It suggested that the participation rate of physical activity among the elderly with disability would be low. The actual level of participation in physical activity is insufficient compared to the positive effects from regular physical activity participation. Therefore, it is very urgent and important to establish strategies to promote physical activity of the elderly with disabilities. In particular, it would be very meaningful to set up a promotion strategy for elderly people with disabilities who are not yet feeling the need for physical activity or who are still in the preparation stage to start any kind of physical activity.

The study of constraints on the elderly with disabilities showed that the keywords such as facilities, disabilities, programs, transportation, gymnasium, discomfort, opportunities, and leisure activities were related to exercise and it suggested that problems related to perception and environment of participating in physical activity among seniors with disability were existed (Koo et al., 2016a). In a study on persons with physical disabilities, it was reported that lack of space, economic problems, lack of time, and difficulty in finding transportation were the factors limiting the physical activity participation (Koo and Oh, 2012). In particular, the poor health status and the absence of partners were the limiting factors of participating in physical activity among older adults (Mannell and Zuzanek, 1991). In addition, Booth et al. (2000) reported that safety, social support, and accessibility to the physical activity facilities were as predictors of participation in the physical activity of the elderly. In addition, the possibility of independent walking, exercise experience, and possibility of conversation were important factors for participating in physical activity among seniors with dementia (Lee et al., 2011). Therefore, in order to promote the physical activity of the elderly with disabilities who have unique needs in terms of disability and aging, it is necessary to establish strategies based on function and/or structure, activities and participation, as well as individual factors and environmental factors.

This study was based on previous studies such as a systematic literature review on an analysis of physical activity participation facilitators among seniors with physical disabilities (Koo et al., 2016b), restrictions of physical activity participation in older adults with disability (Koo et al., 2016a), and investigating factors for physical activity of elderly with physical disability employing International Classification of Functioning, Disability and Health (Koo et al., 2017) to investigate an individual process of changing exercise behavior and applying that information were developed for physical activity promoting strategies for elderly with disabilities. The concept of change process has been studied as an important predictor to explain the stage of change in behavior and is a cognitive and behavioral activity that individuals use to modify their behavior. This process of change is composed of 10 subvariables: consciousness raising (CR), dramatic relief (DR), environmental re-evaluation (ER), self-reevaluation (SR), social liberation (SL), counter conditioning (CC), helping relationship (HR), reinforcement management (RM), self-liberation (SeL), and stimulus control (SC) (Prochaska et al., 1988).

The purpose of this study was to develop physical activity promotion strategies for sedentary disabled older adults who were in the stage of precontemplation, contemplation, and preparation utilizing the transtheoretical model for their health and healthy lifestyle. The results from the study will provide useful information for older adults with disabilities, family members who take care of disabled seniors, policy makers, practitioners, and researchers.

\section{MATERIALS AND METHODS}

\section{Study procedures}

Based on the data collected through the preliminary studies and the survey results of the changes in the exercise behavior of the elderly with disabilities, three researchers and four research assistants developed promoting physical activity strategies for the elderly with disability. The strategies were verified by 22 experts and they were revised based on the verification results. In addition, the methods and results were presented at the American College of Sport Medicine Annual Meeting in 2016 to receive any valuable feedback. The process of the study is shown below Fig. 1 .

\section{Study subjects}

To develop physical activity promotion strategies for the elderly with disability, the participants of this study were sampled from the elderly with disability (over 60 years old) employing the convenience sampling who had physical disability and/or brain lesions and who were at one of the stages of change for physical activity: precontemplation, contemplation, and preparation. Researchers visited the elderly welfare centers and the welfare centers for the disabled from May to June, 2014 to collect data. Researchers explained the purpose of the study and the data was collected from 


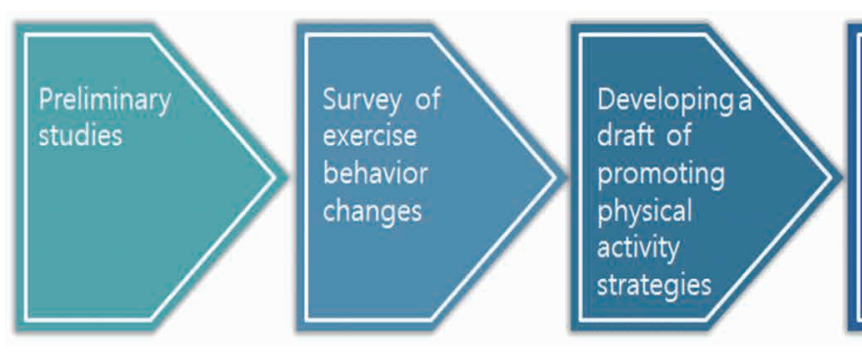

Table 1. Characteristics of the participants

\begin{tabular}{lc}
\hline Variable & No. $(\%)$ \\
\hline Gender & \\
Male & $43(53.1)$ \\
Female & $38(46.9)$ \\
Age (yr) & \\
$60-64$ & $19(23.5)$ \\
$65-69$ & $19(23.5)$ \\
$70-74$ & $13(16.0)$ \\
$75-79$ & $12(14.8)$ \\
$>80$ & $18(22.2)$ \\
Grade of disability & \\
1 & $3(3.7)$ \\
2 & $25(30.9)$ \\
3 & $19(23.5)$ \\
4 & $11(13.6)$ \\
5 & $13(16.0)$ \\
6 & $10(12.3)$ \\
Stage of behavior change & \\
Precontemplation & $33(40.7)$ \\
Contemplation & $33(40.7)$ \\
Preparation & $15(18.5)$ \\
Total & $81(100)$ \\
\hline
\end{tabular}

the elderly with disability who voluntarily agreed to participate in the study. The demographic characteristics of the participants are shown in Table 1.

The validity of the proposed physical activity promotion strategies was conducted by the expert group. The 22 experts were selected from each field that was closely related to in this study including a rehabilitation specialist, six professors and specialists in the field of special physical education and aging and physical activity, a professor in the area of social welfare and 14 exercise leaders working for the elderly with disability.

\section{Measurements}

The stages of changes for exercise behavior and processes of exercise behavior change were used for collecting data. The stages of

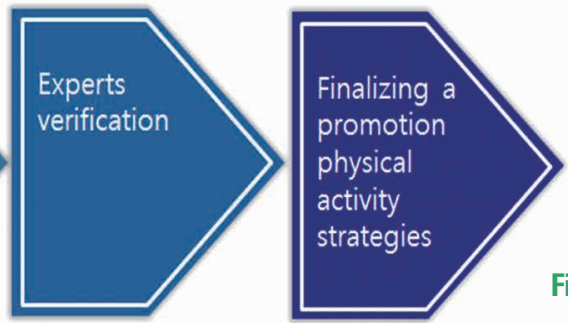

Fig. 1. The process of the study.
Table 2. Reliability of processes of exercise behavior change

\begin{tabular}{ccccccccccc} 
CR & DR & ER & SR & SL & CC & HR & RM & SeL & SC \\
\hline Cronbach $\alpha$ & 0.811 & 0.791 & 0.868 & 0.838 & 0.718 & 0.841 & 0.835 & 0.877 & 0.851 & 0.881
\end{tabular}

$C R$, consciousness raising; $D R$, dramatic relief; $E R$, environmental reevaluation; $S R$, self-re-evaluation; SL, social liberation; CC, counter conditioning; HR, helping relationships; RM, reinforcement management; SeL, self-liberation; SC, stimulus control.

changes for exercise behavior which employed by Cardinal et al. (1998) were translated into Korean. Additionally, the survey items were used from processes of exercise behavior change scale by Nigg et al. (1999) based on the concept of change process proposed by Prochaska and Diclemente (1983), and translated it into Korean (Kim, 2002). The questionnaire consisted of 10 factors including CR, DR, ER, SR, SL, CC, HR, RM, SeL, and SC. 5-likert scale from 'strongly agree (1 point)' to 'strongly disagree (5 points)' were used and then analyzed by reverse scoring. The internal consistency reliability Cronbach $\alpha$ value was ranged from 0.718 to 0.881 . and Cronabch $a$ value for each factor is shown in Table 2.

\section{Statistical analysis}

Frequency analysis and descriptive statistical analysis with IBM SPSS ver. 18.0 (IBM Co., Armonk, NY, USA) were used to analyze all the collected data. In addition, one-way analysis of variance (ANOVA) was performed to investigate the difference between the processes of exercise behavior change according to the stages of change for exercise behavior, and then scheffe was conducted to find out which pairs of means were significant.

\section{RESULTS}

\section{Each level of exercise behavior changing process}

In this study, the promotion strategies were limited for the elderly with disabilities in the physical activity behavior change stage of precontemplation, contemplation, and preparation, which was thought to require more facilitation strategies than the older adults with disabilities who was in the stage of action and mainte- 
Table 3. Process of exercise behavior change based on the stage of exercise behavior change

\begin{tabular}{|c|c|c|c|c|c|c|c|}
\hline \multirow{2}{*}{$\begin{array}{c}\text { Process of exercise } \\
\text { behavior change }\end{array}$} & \multirow{2}{*}{$\begin{array}{c}\text { Total } \\
\text { Mean } \pm \text { SD }\end{array}$} & \multicolumn{2}{|c|}{ Precontemplation stage } & \multicolumn{2}{|c|}{ Contemplation stage } & \multicolumn{2}{|c|}{ Preparation stage } \\
\hline & & Mean \pm SD & Order & Mean $\pm S D$ & Order & Mean $\pm S D$ & Order \\
\hline $\mathrm{CR}$ & $6.74 \pm 3.08$ & $5.61 \pm 3.03$ & 9 & $6.85 \pm 2.82$ & 9 & $9.00 \pm 2.54$ & 9 \\
\hline DR & $9.46 \pm 3.06$ & $8.45 \pm 2.73$ & 4 & $9.73 \pm 2.99$ & 5 & $11.07 \pm 3.26$ & 6 \\
\hline ER & $10.81 \pm 2.77$ & $10.79 \pm 2.60$ & 1 & $10.30 \pm 2.91$ & 3 & $12.00 \pm 2.62$ & 2 \\
\hline SR & $10.15 \pm 3.15$ & $9.30 \pm 3.03$ & 3 & $10.00 \pm 3.10$ & 4 & $12.33 \pm 2.61$ & 1 \\
\hline$S L$ & $8.74 \pm 2.91$ & $8.06 \pm 2.47$ & 6 & $8.24 \pm 2.96$ & 8 & $11.33 \pm 2.38$ & 3 \\
\hline CC & $7.95 \pm 3.23$ & $6.97 \pm 2.76$ & 8 & $8.36 \pm 3.58$ & 7 & $9.20 \pm 2.93$ & 8 \\
\hline$H R$ & $8.65 \pm 3.35$ & $7.85 \pm 3.08$ & 7 & $8.91 \pm 3.67$ & 6 & $9.87 \pm 2.90$ & 7 \\
\hline $\mathrm{RM}$ & $10.75 \pm 2.58$ & $10.18 \pm 2.60$ & 2 & $11.06 \pm 2.59$ & 1 & $11.33 \pm 2.41$ & 3 \\
\hline SeL & $9.73 \pm 3.14$ & $8.18 \pm 3.02$ & 5 & $10.55 \pm 2.96$ & 2 & $11.33 \pm 2.35$ & 3 \\
\hline SC & $6.32 \pm 3.19$ & $5.09 \pm 2.39$ & 10 & $6.45 \pm 2.78$ & 10 & $8.73 \pm 4.17$ & 10 \\
\hline
\end{tabular}

SD, standard deviation; CR, consciousness raising; DR, dramatic relief; ER, environmental reevaluation; SR, self-re-evaluation; SL, social libera-tion; CC, counter conditioning; HR, helping relationships; RM, reinforcement management; SeL, self-liberation; SC, stimulus control.

nance. Table 3 shows the results of the behavior change process based on the stage of physical activity behavior change.

As shown in Table 3, in the stage of precontemplation, ER, RM, SR, DR were appeared in order, and in the stage of contemplation, RM, SeL, ER, SR were appeared to be important in the process of exercise behavior change. Additionally, SR, ER, SL, RM, SeL were showed in order in the stage of preparation. The results of the ANOVA analysis are summarized in Table 4.

As shown in Table 4, among the sub-factors of exercise behavior change, there are significant difference in $\mathrm{CR}(F=7.299, P<0.01)$, DR $(F=4.309, P<0.05)$, SR $(F=5.372, P<0.01), \mathrm{SL}(F=8.729$, $P<0.001), \operatorname{SeL}(F=8.396, P<0.001)$, and SC $(F=7.976, P<0.01)$. However, there was no significant difference in ER, CC, HR, and $\mathrm{RM}$. The results of the Scheffe analysis on the factors showing significant difference between groups demonstrated that the preparation stage in $\mathrm{CR}, \mathrm{DR}$, and $\mathrm{SC}$ were higher than the precontemplation stage. SR and SL were higher in the preparation stage comparing with the precontemplation stage and the contemplation stage. Additionally, SeL was higher in the contemplation and preparation stages comparing with the precontemplation stage. This result was consistent with the previous study (Lee, 2004), in which people who were in the contemplation stage comparing with the precontemplation stage and the preparation stage comparing with the contemplation stage employed more the change process.

\section{Expert validity check on exercise behavior changing strategies}

Based on this study results related to each exercise behavior change process, the researchers conducted five in-depth meetings to develop a draft of physical activity promotion strategies in each stage of precontemplation, contemplation, and preparation. Then the developed strategies were checked their validity from the experts in the fields and academia. In the validity check, the score was selected from 1 to 5 points for validity at each stage, and additional comments were collected. The results are as follows. The averages were found to be relatively valid as $3.95 \pm 0.84$ for the precontemplation stage, $4.09 \pm 0.81$ for the contemplation stage, and $4.05 \pm 0.65$ for the preparation stage. The following is the results of the validity check for physical activity promoting strategies for each stage of the exercise behavior change (Table 5).

The additional opinions from the experts about promotion strategies in each stage of exercise behavior change were summarized and the comments are as follows (Table 6).

\section{Strategies for promoting physical activity of the older adults with disabilities}

Based on the validity check and the expert comments, the modified physical activity promotion strategies for each stage of exercise behavior change for the elderly with disabilities are as follows.

In the precontemplation stage (Table 7), the benefits from participating in regular physical activity such as physical and mental health, reduction of medical expenses, and increasing positive emotions should be continuously informed. Health professionals including physicians should deliver the reliable messages that physical inactivity lifestyles could bring various health problems and the burden on families and the society. Local health care and physical activity authorities should draw attention to physical activity through public relation projects for elderly people with disabilities. It is also necessary for the physician to persuade their elderly patients to participate in the physical activity during the 
Table 4. One-way analysis of variance results on process of exercise behavior change based on the stage of exercise behavior change

\begin{tabular}{|c|c|c|c|c|c|c|}
\hline Process of exercise behavior change & Group & No. & Mean \pm SD & $F$ & $P$-value & Scheffe \\
\hline \multirow[t]{3}{*}{$\mathrm{CR}$} & Precontemplation (A) & 33 & $5.61 \pm 3.03$ & 7.299 & $0.001^{* *}$ & $A<C$ \\
\hline & Contemplation (B) & 33 & $6.85 \pm 2.82$ & & & \\
\hline & Preparation (C) & 15 & $9.00 \pm 2.54$ & & & \\
\hline \multirow[t]{3}{*}{ DR } & Precontemplation (A) & 33 & $8.45 \pm 2.73$ & 4.309 & $0.017^{*}$ & $A<C$ \\
\hline & Contemplation (B) & 33 & $9.73 \pm 2.99$ & & & \\
\hline & Preparation (C) & 15 & $11.07 \pm 3.26$ & & & \\
\hline \multirow[t]{3}{*}{ ER } & Precontemplation (A) & 33 & $10.79 \pm 2.60$ & 1.991 & 0.143 & \\
\hline & Contemplation (B) & 33 & $10.30 \pm 2.91$ & & & \\
\hline & Preparation (C) & 15 & $12.00 \pm 2.62$ & & & \\
\hline \multirow[t]{3}{*}{ SR } & Precontemplation (A) & 33 & $9.30 \pm 3.03$ & 5.372 & $0.007^{* *}$ & $\mathrm{~A}<\mathrm{C}, \mathrm{B}<\mathrm{C}$ \\
\hline & Contemplation (B) & 33 & $10.00 \pm 3.10$ & & & \\
\hline & Preparation (C) & 15 & $12.33 \pm 2.61$ & & & \\
\hline \multirow[t]{3}{*}{ SL } & Precontemplation (A) & 33 & $8.06 \pm 2.47$ & 8.729 & $0.000^{* * *}$ & $A<C, B<C$ \\
\hline & Contemplation (B) & 33 & $8.24 \pm 2.96$ & & & \\
\hline & Preparation (C) & 15 & $11.33 \pm 2.38$ & & & \\
\hline \multirow[t]{3}{*}{ CC } & Precontemplation (A) & 33 & $6.97 \pm 2.76$ & 3.067 & 0.052 & \\
\hline & Contemplation (B) & 33 & $8.36 \pm 3.58$ & & & \\
\hline & Preparation (C) & 15 & $9.20 \pm 2.93$ & & & \\
\hline \multirow[t]{3}{*}{$H R$} & Precontemplation (A) & 33 & $7.85 \pm 3.08$ & 2.086 & 0.131 & \\
\hline & Contemplation (B) & 33 & $8.91 \pm 3.67$ & & & \\
\hline & Preparation (C) & 15 & $9.87 \pm 2.90$ & & & \\
\hline \multirow[t]{3}{*}{ RM } & Precontemplation (A) & 33 & $10.18 \pm 2.60$ & 1.442 & 0.243 & \\
\hline & Contemplation (B) & 33 & $11.06 \pm 2.59$ & & & \\
\hline & Preparation (C) & 15 & $11.33 \pm 2.41$ & & & \\
\hline \multirow[t]{3}{*}{ SeL } & Precontemplation (A) & 33 & $8.18 \pm 3.02$ & 8.396 & $0.000^{* * *}$ & $A<B, C$ \\
\hline & Contemplation (B) & 33 & $10.55 \pm 2.96$ & & & \\
\hline & Preparation (C) & 15 & $11.33 \pm 2.35$ & & & \\
\hline \multirow[t]{3}{*}{ SC } & Precontemplation (A) & 33 & $5.09 \pm 2.39$ & 7.976 & $0.001^{* *}$ & $A<C$ \\
\hline & Contemplation (B) & 33 & $6.45 \pm 2.78$ & & & \\
\hline & Preparation (C) & 15 & $8.73 \pm 4.17$ & & & \\
\hline
\end{tabular}

SD, standard deviation; CR, consciousness raising; DR, dramatic relief; ER, environmental reevaluation; SR, self-re-evaluation; SL, social liberation; CC, counter conditioning; $H R$, helping relationships; $\mathrm{RM}$, reinforcement management; SeL, self-liberation; SC, stimulus control.

${ }^{*} P<0.05 .{ }^{* *} P<0.01 .{ }^{* * *} P<0.001$.

physical examination. In addition, it is important to educate guardians of older adults with disabilities because the guardians could play a big role to help and give an advice to seniors with disabilities.

It provides an opportunity to experience not only the cognitive approach but also the refreshing mood and health benefits of physical activity. At this time, the experience of physical activity can induce interest, reduce uneasiness, and can play a big role in changing thoughts about physical activity. The government and health care organizations provide frequent opportunities to enjoy easy and safe physical activity programs for the seniors with disabilities. Also, demonstrating a healthy disabled elderly who can regularly participate in physical activity as a model, let the seniors with disabilities learn how to overcome the difficulties of doing physical activities and encourage them to have healthy lifestyles.

At the contemplation stage (Table 8), it helps to motivate the seniors with disabilities to participate in physical activities by continuously recognizing the necessity of physical activity for maintaining their health and by seeing the peer participating in physical activity or by exposing the peer to exercise with exercise instructor. In addition, the ways from different angles to recognize and reinforce older adults with disabilities about the positive aspects of regularly participating in physical activity such as health maintenance and improvement, physical function recovery, delayed aging, formation of self-reliance, acquisition of opportunities for social networking, and quality of life of the family should be 
Table 5. Evaluation of promotion strategies for each level of exercise behavior change

\begin{tabular}{llccc}
\hline \multirow{2}{*}{ Respondent } & Classifica- & \multicolumn{3}{c}{ Stage } \\
\cline { 3 - 5 } & tion & Precontemplation & Contemplation & Preparation \\
\hline Kim 00 & Field & 4 & 4 & 4 \\
Jung 00 & Field & 4 & 4 & 4 \\
Jang 00 & Academic & 4 & 4 & 4 \\
Lee 00 & Field & 2 & 2 & 5 \\
Lee 00 & Field & 4 & 4 & 4 \\
Lee 00 & Field & 4 & 5 & 4 \\
Lee 00 & Field & 2 & 4 & 3 \\
Song 00 & Field & 5 & 5 & 5 \\
Kim 00 & Field & 4 & 4 & 4 \\
Kim 00 & Academic & 4 & 4 & 4 \\
Kim 00 & Academic & 4 & 3 & 4 \\
Kim 00 & Academic & 4 & 5 & 4 \\
King 00 & Field & 5 & 4 & 3 \\
Kim 00 & Academic & 4 & 4 & 5 \\
Kim 00 & Academic & 3 & 3 & 3 \\
Park 00 & Field & 4 & 5 & 4 \\
Lee 00 & Field & 5 & 5 & 5 \\
Jung 00 & Field & 5 & 5 & 5 \\
Jo 00 & Field & 4 & 4 & 4 \\
Oh 00 & Academic & 3 & 3 & 3 \\
Kim 00 & Academic & 5 & 5 & 4 \\
Jung 00 & Field & 4 & 4 & 4 \\
Mean \pm SD & & $3.95 \pm 0.84$ & $4.09 \pm 0.81$ & $4.05 \pm 0.65$ \\
\hline SD & & & 4 \\
\hline
\end{tabular}

SD, standard deviation. found and implemented. When opportunities or guidance of physical activity are provided, older adults with disabilities can select from several alternatives depending on the situation, condition, and circumstances.

It also encourages family members, such as spouses, children,

Table 7. Physical activity promotion strategies for precontemplation stage

Precontemplation stage
Emphasis on the importance of physical activity
Increase frequency of health communication exposure
Continued interest and publicity by administrative authorities
Take advantage of health checkup
Education and promotion for guardians and acquaintances
Positive experiences and recognition through expansion of participation opportunities
Exposure to various participation opportunities of welfare organizations and differ-
ent organizations
Use a peer group model

Table 8. Physical activity promotion strategies for contemplation stage

Contemplation stage
Engage peers and professionals and provide various opportunities of physical
activity participation
Emphasis on positive effects of physical activity (exercise)
Suggest alternative ways to participate in physical activity (exercise)
Build a family member utilization system
Conduct a recognition improvement program
Increase participation opportunities through peer teaching methods

Table 6. Additional expert feedback

\begin{tabular}{|c|c|c|}
\hline Precontemplation stage & Contemplation stage & Preparation stage \\
\hline $\begin{array}{l}\text { In order to increase the motivation, exercise informa- } \\
\text { tion should be provided from friends and adapted } \\
\text { physical activity leaders. }\end{array}$ & $\begin{array}{l}\text { Applying a peer group system for encouraging physi- } \\
\text { cal activity motivation and preparing for exercise } \\
\text { preparation stage }\end{array}$ & $\begin{array}{l}\text { Applying a peer group system for encouraging physi- } \\
\text { cal activity (exercise) participation and leading regu- } \\
\text { lar physical activity (exercise) }\end{array}$ \\
\hline $\begin{array}{l}\text { Development of a peer group supporting system in } \\
\text { the aspect of emphasizing on physical activity bene- } \\
\text { fits and motivation } \\
\text { Need to solve economic problems }\end{array}$ & $\begin{array}{l}\text { Role of guardians, who could par-ticipate in physical } \\
\text { activity with disabled senior, should be emphasized. } \\
\text { A model should be presented for easy understanding } \\
\text { of the result. }\end{array}$ & $\begin{array}{l}\text { Demonstrating the need for regular physical activity } \\
\text { (exercise) participation } \\
\text { Organizing and providing appro-priate physical activity } \\
\text { (exercise) programs for individuals }\end{array}$ \\
\hline $\begin{array}{l}\text { For providing advice on exercise participation, empha- } \\
\text { sizing the role of guardians in the different stages of } \\
\text { exercise behavior change } \\
\text { For overcome mobility among seniors with disabilities, } \\
\text { it is necessary to train the guardians. }\end{array}$ & $\begin{array}{l}\text { It is necessary to deliver positive messages about } \\
\text { exercise. } \\
\text { It is necessary to provide specific alternatives for exer- } \\
\text { cise participation }\end{array}$ & $\begin{array}{l}\text { Setting specific physical activity (exercise) goals and } \\
\text { providing a chance to experience an achievement } \\
\text { Emphasizing interest and advantages when seniors } \\
\text { with disabilities participate in physical activities } \\
\text { (exercise) }\end{array}$ \\
\hline $\begin{array}{l}\text { It is necessary to reestablish concepts of physical } \\
\text { activity (exercise). }\end{array}$ & & \\
\hline \multicolumn{3}{|l|}{$\begin{array}{l}\text { It is necessary to increase physical activity opportuni- } \\
\text { ties, emphasize and educate importance of physical } \\
\text { activity. }\end{array}$} \\
\hline Need to change thoughts about health. & & \\
\hline
\end{tabular}


Table 9. Physical activity promotion strategies for preparation stage

Preparation stage

Maintain a positive psychological state

Develop programs based on disability type and person's characteristics

Improving the environment, accessibility, facilities, equipment, etc.

Provide psychological care program

Develop expert-based effective long-term goals

Use a specific goal setting and psychological feedback

and relatives, to build support systems that are tailored to the individual circumstances in which they are able to participate in physical activity, while encouraging family members to participate in physical activity programs with the disabled seniors and give them positive messages and courage. At this time, it helps to rebuild and recreate the negative experience of physical activity that has been acquired due to disability or other reasons as a positive experience. It is also desirable to motivate the disabled older adults to participate in physical activity programs with people who have similar types or degrees of disability or with their peers, thereby motivating them to participate in physical activity and building a social network.

In the preparation phase (Table 9), the elderly with disabilities should be provided with a positive experience of physical activity. It is necessary to construct appropriate physical activity programs based on the type and degree of disability of the elderly with disabilities. Also, providing institutional systems that can secure accessibility and mobility of disabled elderly people to participate in the physical activity program is important and necessary information of accessibility and mobility should be provided. Problems with Physical function and lack of facilities to meet different types of disability make it more difficult for older adults with disabilities to participate in physical activity, so the least restrictive environment should be provided. When the disabled elderly people participate in physical activity, health professionals help them to reconfigure and have a new understanding of emotional and cognitive aspects of their own problems so that they can have the belief that they can be physically and mentally healthy.

Furthermore, it is important to note that accomplishments at the beginning of the preparation phase have a positive impact on ongoing participation, and encourage the disabled seniors to develop their own achievable goals. Older people with disabilities should set specific goals, establish realistic long- and short-term goals, evaluate the goals on their own, and participate in the design of physical activity programs. It is necessary for elderly people with disabilities to clarify the goals they want to accomplish and to encourage them to achieve their goals. In the case of shortterm goals, it is necessary to establish measurable and concrete goals such as 'exercise twice a week' for employing their own psychological feedback.

Finally, the promotion strategies of the elderly people with disabilities need general administrative support, institutional system construction and policy support. We found out that on the basis of these system, various fields of expert groups complementarily cooperating could promote the physical activity behavior changes of the elderly with disabilities. In other words, it is necessary to constantly check and publicize the actual concerns for the seniors with disabilites from the stage of precontemplation to preparation and to employing elderly peer groups would be influential. When the results from the study continuously apply and maintain for older adults with disabilites, it may be possible to induce disabled elderly people to regularly participate in the physical activity for their quality of life.

\section{CONFLICT OF INTEREST}

No potential conflict of interest relevant to this article was reported.

\section{ACKNOWLEDGMENTS}

This work was supported by the National Research Foundation of Korea Grant funded by the Korean Government (NRF-2013S1A5A2A03045717).

\section{REFERENCES}

Booth ML, Owen N, Bauman A, Clavisi O, Leslie E. Social-cognitive and perceived environment influences associated with physical activity in older Australians. Prev Med 2000;31:15-22.

Campbell M, Kemp B. Variation in secondary conditions, risk factors, and health care needs for four groups of persons aging with physical disability. J Rehabil Res Dev 1997;34:119-120.

Cardinal BJ, Engels HJ, Zhu W. Application of the transtheoretical model of behavior change to preadolescents' physical activity and exercise behavior. Pediatr Exerc Sci 1998;10:69-80.

Di Francesco V, Zamboni M, Zoico E, Bortolani A, Maggi S, Bissoli L, Zivelonghi A, Guariento S, Bosello O. Relationships between leisure-time physical activity, obesity and disability in elderly men. Aging Clin Exp Res 2005;17:201-206.

Foreman P. Aging and disability: double jeopardy? J Intellect Dev Disabil 
1998;23;1-2

Giné-Garriga M, Guerra M, Unnithan VB. The effect of functional circuit training on self-reported fear of falling and health status in a group of physically frail older individuals: a randomized controlled trial. Aging Clin Exp Res 2013;25:329-336.

Kim CJ. Process of change, decisional balance and self-efficacy corresponding to the stage of exercise behavior in patients with type 2 diabetes mellitus. J Korean Acad Adult Nurs 2002;14:83-92.

Koo KM, Kim CJ, Park CH, Byeun JK, Seo GW. Restrictions of physical activity participation in older adults with disability: employing keyword network analysis. J Exerc Rehabil 2016a;12:373-378.

Koo KM, Kim CJ, Park CH, Seo GW, Byeun JK, Kim YU, Lim NH. The study of physical activity participation facilitators analysis for older adults with physical disabilities. J Sport Leisure Stud 2016b;63:621-638.

Koo KM, Oh AR. Analysis on the constraint factors of physical disabilities in the lifetime sport. Korean J Phys Educ 2012;51:447-454.

Koo KM, Park CH, Kim CJ. Exploring factors for physical activity improvement of older adults with physical disabilities: Preliminary study applying international classification of functioning, disability and health (ICF). J Sport Leisure Stud 2017;68:483-493.

Korean Paralympic Committee. 2011 people with disabilities living physical education participation survey. Seoul: Korean Paralympic Committee press; 2011.

Lee BH, Park JS, Kim NR. The effect of physical activity program on cognitive function, physical performance, gait, quality of life and depression in the elderly with dementia. J Spec Educ Rehabil Sci 2011;50:307328.

Lee YM. Process of change, decisional balance and self efficacy corresponding to stages of change in exercise behaviors in middle aged women. J Korean Acad Nurs 2004;34:362-371.

Mangani I, Cesari M, Kritchevsky SB, Maraldi C, Carter CS, Atkinson HH, Penninx BW, Marchionni N, Pahor M. Physical exercise and comor- bidity. Results from the Fitness and Arthritis in Seniors Trial (FAST). Aging Clin Exp Res 2006;18:374-380.

Mannell RC, Zuzanek J. The nature and variability of leisure constraints in daily life: the case of the physically active leisure of older adults. Leisure Sci 1991;13:337-351.

Ministry of Health and Welfare. 2011 Elderly Korea institute for Health and social affairs. Seoul (Korea): Ministry of Health and Welfare; 2012.

Nigg CR, Burbank PM, Padula C, Dufresne R, Rossi JS, Velicer WF, Laforge RG, Prochaska JO. Stages of change across ten health risk behaviors for older adults. Gerontologist 1999;39:473-482.

Prochaska JO, DiClemente CC. Stages and processes of self-change of smoking: toward an integrative model of change. J Consult Clin Psychol 1983;51:390-395.

Prochaska JO, Velicer WF, DiClemente CC, Fava J. Measuring processes of change: applications to the cessation of smoking. J Consult Clin Psychol 1988;56:520-528.

Rejeski WJ, Marsh AP, Chmelo E, Rejeski JJ. Obesity, intentional weight loss and physical disability in older adults. Obes Rev 2010;11:671-685.

Riebe D, Blissmer BJ, Greaney ML, Garber CE, Lees FD, Clark PG. The relationship between obesity, physical activity, and physical function in older adults. J Aging Health 2009;21:1159-1178.

Sheets DJ. Aging with disability: ageism and more. Generations 2005;29: 37-41.

Tak E, Staats P, Van Hespen A, Hopman-Rock M. The effects of an exercise program for older adults with osteoarthritis of the hip. J Rheumatol 2005;32:1106-1113.

Verbrugge LM, Yang L. Aging with disability and disability with aging. J Disabil Policy Stud 2002;12:253-267.

Warburton DE, Nicol CW, Bredin SS. Health benefits of physical activity: the evidence. CMAJ 2006;174:801-809.

Yang HT, Shin WW. The study on characteristics of the elderly with disability. Korean J Gerontol Soc Welf 2011;52:255-278. 